\title{
INEQUALITIES FOR DISCRETE HIGHER ORDER CONVEX FUNCTIONS
}

\author{
ANDRÁS PRÉKOPA
}

Mathematics subject classification (2000): 52A41.

Keywords and phrases: inequalities; higher order convex functions; expectation inequalities; power moment problem;.

\section{REFERENCES}

[1] E. Boros And A. PrÉKopa, Closed Form Two-Sided Bounds for Probabilities That Exactly $r$ and at Least $r$ out of $n$ Events Occur, Mathematics of Operations Research, 14 (1989), 317-342.

[2] D. Dawson And A. SAnkoff, An Inequality for Probabilities, Proceedings of the American Mathematical Society, 18 (1967), 504-507.

[3] H.P. Edmundson, Bounds on the Expectation of a Convex Function of a Random Variable, The RAND Corporation, P-982, April 9, 1957.

[4] M. Fréchet, Les Probabilités Associées à un Système d'Événement Compatibles et Dépendants, Actualités Scientifiques Industrielles, Nos. 859, 942, Paris, 1940, 1943.

[5] A. Gilányi And Zs. PÁles, On Convex Functions of Higher Order, Math. Inequalities and Appl., 11 (2008), 271-282.

[6] A. Goberna And M.A. Lopez, Linear Semi-Infinite Optimization, Wiley, New York, 1998.

[7] J.L. JENSEN, Sur les fonctions convexes et les inégalités entre les valeurs moyennes, Acta Math., 30 (1906), 175-193.

[8] C. Jordan, Calculus of Finite Differences, Chelsea Publishing Company, New York, 1947.

[9] S. Karlin And W.J. Studden, Tchebycheff Systems: With Applications in Analysis and Statistics, Interscience, New York, 1966.

[10] J.H.B. Kemperman, The General Moment Problem, a Geometric Approach, Ann. Math. Statist., 39 (1968), 93-122.

[11] S.M. Kwerel, Most Stringent Bounds on Aggregated Probabilities of Partially Specified Dependent Probability Systems, Journal of the American Statistical Association, 70 (1975), 472-479.

[12] C.E. Lemke, The Dual Method for Solving the Linear Programming Problem, Naval Research Logistic Quarterly, 1 (1954), 36-47.

[13] A. MADANSKY, Bounds on the Expectation of a Convex Function of a Multivariate Random Variable, Annals of Math. Stat., 30, 743-746.

[14] P.J. Olver, On Multivariate Interpolation, School of Math., Univ. of Minnesota, MN, 2005.

[15] J. PeČARIĆ And V. ČUlJaK, Interpolation Polynomials and Convex Functions of Higher Order, Math. Inequalities and Appl., 5 (2002), 369-386.

[16] T. Popoviciu, Sur quelques propriétés des fonctions d'une ou de deux variables réelles, Mathematica (Cluj), 8 (1934), 1-85.

[17] T. Popoviciu, Les Fonctions Convexes. Actualités Scientifiques et Industrielles 992, Hermann, Paris, France, 1944.

[18] A. PRÉKopA, Boole-Bonferroni Inequalities and Linear Programming, Oper. Res., 36 (1988), 145162.

[19] A. PRÉKopa, The Discrete Moment Problem and Linear Programming, Discrete Applied Mathematics, 27 (1990), 235-254. 
[20] A. PréKopa, Inequalities on Expectations Based on the Knowledge of Multivariate Moments, M. Shaked, Y.L. Tong, eds., Stochastic Inequalities. Institute of Mathematical Statistics. Lecture Notes-Monograph Series, Vol. 22. Institute of Mathematical Statistics, Hayward, CA, 309-331, 1992.

[21] A. PRÉKopA, Stochastic Programming, Kluwer Academic Publishers, Dordrecht, Boston, 1995.

[22] A. PRÉKOPA, A Brief Introduction to Linear Programming, Math. Scientist, 21 (1996), 85-111.

[23] A. PRÉKOPA, On Multivariate Discrete Higher Order Convex Functions and Their Applications, Proc. Sixth Internat. Conf. on Generalized Convexity and Monotonicity, August 29-September 2. Karlovasi, Samos, Greece, Lecture Notes in Economics and Mathematical Systems, Springer, Heidelberg, Germany, 21-47.

[24] A. Prékopa And G. Alexe, Dual Methods for the Numerical Solution of the Univariate Power Moment Problem, RUTCOR Research Report 14-2003.

[25] A. Prékopa And S. SZedmák, On the Numerical Solution of Discrete Power Moment Problem, RUTCOR Research Report 99-2002, Rutgers University, Piscataway, NJ.

[26] L. TAKÁCs, On the Method of Inclusion and Exclusion, Journal of the American Mathematical Association, 62 (1967), 102-113.

[27] L. RichARD TURNER, Inverse of the Vandermonde Matrix with Applications, NASA Technical Note D-3547. 